\title{
Novel and promising compounds to treat Cryptosporidium parvum infections
}

\author{
Zofi Graczyk • Lidia Chomicz • Mariola Kozlowska • \\ Zygmunt Kazimierczuk • Thaddeus K. Graczyk
}

Received: 18 October 2010 / Accepted: 9 February 2011 /Published online: 23 February 2011

(C) The Author(s) 2011. This article is published with open access at Springerlink.com

\begin{abstract}
No fully effective approved drug therapy exists for Cryptosporidium infections of immunocompetent and immunocompromised patients. Here, we investigated 11 benzimidazole derivatives carrying substituted thioalkyl and thiobenzyl groups at position 2 of benzimidazole nucleus and additional substituents at the benzene part of benzimidazole for inhibition of the in vitro growth of the intestinal protozoan parasite, Cryptosporidium parvum. Three of them, i.e., 5-carboxy-2-(4-nitrobenzylthio)1H-benzimidazole, 5,6-dichloro-2-(4-nitrobenzylthio)1H-benzimidazole, and 4,6-dichloro-2-(4-nitrobenzylthio)$1 \mathrm{H}$-benzimidazole, (compounds 5, 7, and $\mathbf{8}$ ) were the most active $\left(\mathrm{IC}_{50} 28-31 \mu \mathrm{M}\right)$. The concentration of compounds 5,7 , and 8 that caused $50 \%$ growth inhibition in human enterocytic HCT-8 cells by a quantitative alkaline phosphatase immunoassay was comparable with those obtained for paromomycin.
\end{abstract}

Z. Graczyk

W. Stefanski Institute of Parasitology, PAN,

Warsaw, Poland

L. Chomicz

Department of Medical Biology, Medical University of Warsaw,

Warsaw, Poland

M. Kozłowska $\cdot$ Z. Kazimierczuk

Institute of Chemistry, Warsaw University of Life Sciences,

Warsaw, Poland

\section{T. K. Graczyk $(\bowtie)$}

Department of Environmental Health Sciences,

Johns Hopkins Bloomberg School of Public Health,

Baltimore, MD, USA

e-mail: Thaddeus.Graczyk@gmail.com

\section{Introduction}

Cryptosporidium parvum is an important apicomplexan protozoan pathogen that significantly contributes to diarrheal disease in both humans and animals (Downey et al. 2008; Fayer 2004; Graczyk et al. 1997). Throughout the world in immunocompetent hosts, Cryptosporidium infections are generally restricted to the intestinal epithelium, causing acute and self-limiting gastroenteritis. However, for HIV/AIDS patients and other immunocompromised individuals (organs transplant patients), such infection can result in life-threatening diarrheal disease (Ventura et al. 1997). Recently, only nitazoxanide, a nitrothiazole benzamide, was approved by the Food and Drug Administration (FDA) for the treatment of cryptosporidiosis in immunocompetent adults and children over 1 year old (Anderson and Curann 2007). However, this drug is not fully successful for all cases of cryptosporidiosis. Another drug, paromomycin, is well-known as a compound to treat C. parvum infections in animals and cell cultured models. Because Cryptosporidium currently and continuously causes over half of the reported waterborne disease outbreaks associated with exposure in chlorinated public swimming pool water (Dziuban et al. 2006; Ijaz et al. 2000; Sunderland et al. 2007), research on new compounds to treat this disease is in progress.

The benzimidazole nucleus is present in numerous antiparasitic, fungicidal anthelmintic, and antiinflammatory drugs (Andrzejewska et al. 2004; Bennamane et al. 2009; Kazimierczuk et al. 2002). Albendazole, mebendazole, and benzimidazole carbamates affect the cycloskeleton and interact with tubulin of Giardia and other parasitic protozoa (Reynoldson et al. 1992). The various benzimidazole derivatives were investigated as potential antiprotozoan drugs, mainly against Giardia, 
Entamoeba, or Trichomonas species (e.g., Perez-Villaneuva et al. 2010; Hernández-Luis et al. 2010). Therefore, we decided to provide pilot screening tests using the benzimidazole derivatives of our laboratory resources against C. parvum. Of all tested compounds, the most promising appeared to be derivatives of 2-thiobenzimidazole-carrying additive substituents on the heterocyclic ring as well on the S-alkyl-benzyl chains. The major objective of the present study was the search for novel "leading structure" of heterocyclic compounds that would show promise as anticryptosporidial agents.

\section{Materials and methods}

Compounds Paromomycin was purchased from MP Biomedicals (Solon, OH, USA) and was diluted in water just prior to use. The tested compounds were obtained according the methods previously described (Kazimierczuk and Pinna 2004, 2005; Narkhede et al. 2007; Pagano et al. 2004).

C. parvum oocysts C. parvum (Iowa isolate) oocysts were obtained through experimental infection of a female Holstein calf. The protocol for animal infection was approved by the animal care and use committee of the Cornell University, College of Veterinary Medicine, Ithaca, New York, USA. The oocysts were extracted from the feces using continuous-flow centrifugation, purified by cesium chloride gradient centrifugation, and stored at $4{ }^{\circ} \mathrm{C}$ in phosphate-buffered saline (PBS) (pH 7.4) Fig. 1.

Compound activity in cell culture HCT-8 cells were obtained from the American Type Culture Collection (Manassas, VA, USA) and maintained in RPMI 1640 medium supplemented with 10\% Opti-MEM (GIBCO-
BRL, Grand Island, NY, USA), 2\% fetal bovine serum, and $2 \mathrm{mM}$ L-glutamine. To determine in vitro drug efficacy, a quantitative alkaline phosphatase immunoassay was used to measure parasite growth inhibition in cell culture as described previously (Gargala et al. 1999; Woods et al. 1995). Briefly, 96-well, flat-bottom microtiter plates were seeded with $5 \times 10^{4}$ HCT- 8 cells 24 h prior to infection. For infection, the maintenance medium was removed and $5 \times 10^{3}$ oocysts were added to wells in $100 \mu 1$ of RPMI 1640 supplemented with $10 \%$ fetal bovine serum and $0.05 \%$ bile salts. After incubation at $37^{\circ} \mathrm{C}$ for $90 \mathrm{~min}$ to induce excystation and to allow cell invasion, cells were washed once with warm PBS to remove unexcysted oocysts and free sporozoites. Negative control wells to measure background absorbance received $5 \times 10^{3}$ nonviable oocysts subjected to 5 cycles of freezing in liquid nitrogen and thawing in a $37^{\circ} \mathrm{C}$ water bath. Drugs were diluted to appropriate concentrations (Fig. 2) and added to cells in $150 \mu \mathrm{l}$ of parasite growth medium. Paromomycin was used for comparison. Each drug concentration was tested in triplicates in two independent experiments. Plates were first incubated for $48 \mathrm{~h}$ at $37^{\circ} \mathrm{C}$ in $5 \% \mathrm{CO}_{2}-95 \%$ humidified air incubator, and then fixed in $8 \%$ formalin for $2 \mathrm{~h}$ at $22^{\circ} \mathrm{C}$. After fixation, plates were washed three times with PBS and then blocked for $1 \mathrm{~h}$ with $300 \mu \mathrm{l}$ of a blocking solution consisting of $5 \%$ bovine serum albumin (BSA) and $0.002 \%$ Tween 20 in PBS. Rat anti-Cryptosporidium polyclonal sera were diluted 1:500 in a solution of $1 \%$ BSA-0.002\% Tween 20 in PBS, and $50 \mu \mathrm{l}$ was added to each well. After 30 -min incubation at $22^{\circ} \mathrm{C}$, the wells were washed three times with PBS, and $50 \mu \mathrm{l}$ of a horseradish peroxidaseconjugated goat anti-rat secondary antibody diluted 1:2,000 in $1 \%$ BSA- $0.002 \%$ Tween $20-$ PBS was added to each well. After $20 \mathrm{~min}$, plates were washed three times with PBS, and $100 \mu \mathrm{l}$ of a 3,3',5,5'-tetramethylbenzidine

Fig. 1 Structures of tested benzimidazole derivatives<smiles>[R]Sc1nc2c([R])c([R])c([R])c([R])c2[nH]1</smiles>

$1 \mathrm{R}_{1}, \mathrm{R}_{2}, \mathrm{R}_{3}, \mathrm{R}_{4}=\mathrm{H}$

$2 \mathrm{R}_{1}, \mathrm{R}_{3}=\mathrm{Cl}, \mathrm{R}_{2}, \mathrm{R}_{4}=\mathrm{H}$

$3 \mathrm{R}_{1}, \mathrm{R}_{3}=\mathrm{Cl}, \mathrm{R}_{2}, \mathrm{R}_{4}=\mathrm{H}$

$4 \mathrm{R}_{1}, \mathrm{R}_{2}, \mathrm{R}_{3}, \mathrm{R}_{4}=\mathrm{H}$

$5 \mathrm{R}_{1}, \mathrm{R}_{3}, \mathrm{R}_{4}=\mathrm{H}, \mathrm{R}_{2}=\mathrm{COOH}$

$6 \mathrm{R}_{1}, \mathrm{R}_{2}, \mathrm{R}_{3}=\mathrm{H}, \mathrm{R}_{2}=\mathrm{COOH}$

$7 \mathrm{R}_{1}, \mathrm{R}_{4}=\mathrm{H}, \mathrm{R}_{2}, \mathrm{R}_{3}=\mathrm{Cl}$,

$8 \mathrm{R}_{1}, \mathrm{R}_{3}=\mathrm{Cl}, \mathrm{R}_{2}, \mathrm{R}_{4}=\mathrm{H}$

$9 \mathrm{R}_{1}, \mathrm{R}_{3}=\mathrm{Br}, \mathrm{R}_{2}, \mathrm{R}_{4}=\mathrm{H}$

$10 R_{1}, R_{3}, R_{4}=H, R_{2}=$ I

$11 \mathrm{R}_{1}, \mathrm{R}_{2}, \mathrm{R}_{3}, \mathrm{R}_{4}=\mathrm{Br}$

$$
\begin{aligned}
& \mathrm{R}_{5}=\mathrm{n}-\mathrm{C}_{4} \mathrm{H}_{9} \\
& \mathrm{R}_{5}=\mathrm{CH}_{2} \mathrm{CH}_{2} \mathrm{OH} \\
& \mathrm{R}_{5}=\left(\mathrm{CH}_{2}\right)_{3} \mathrm{~N}\left(\mathrm{CH}_{3}\right)_{2} \\
& \mathrm{R}_{5}=\text { benzyl } \\
& \mathrm{R}_{5}=\text {-nitrobenzyl } \\
& \mathrm{R}_{5}=3,4 \text {-dichlorobenzyl } \\
& \mathrm{R}_{5}=4 \text {-nitrobenzyl } \\
& \mathrm{R}_{5}=4 \text {-nitrobenzyl } \\
& \mathrm{R}_{5}=3,5 \text {-dinitrobenzyl } \\
& \mathrm{R}_{5}=3,5 \text {-dinitrobenzyl } \\
& \mathrm{R}_{5}=\text { 4-nitrobenzyl }
\end{aligned}
$$

[Narkhede et al. 2007]

[Andrzejewska et al. 2004]

[Andrzejewska et al. 2004]

[Narkhede et al. 2007]

[Kazimierczuk et al. 2002]

[Kazimierczuk et al. 2002]

[Kazimierczuk et al. 2002]

[Kazimierczuk et al. 2002]

[Kazimierczuk et al. 2005]

[Kazimierczuk et al. 2005]

[Pagano et al. 2004] 


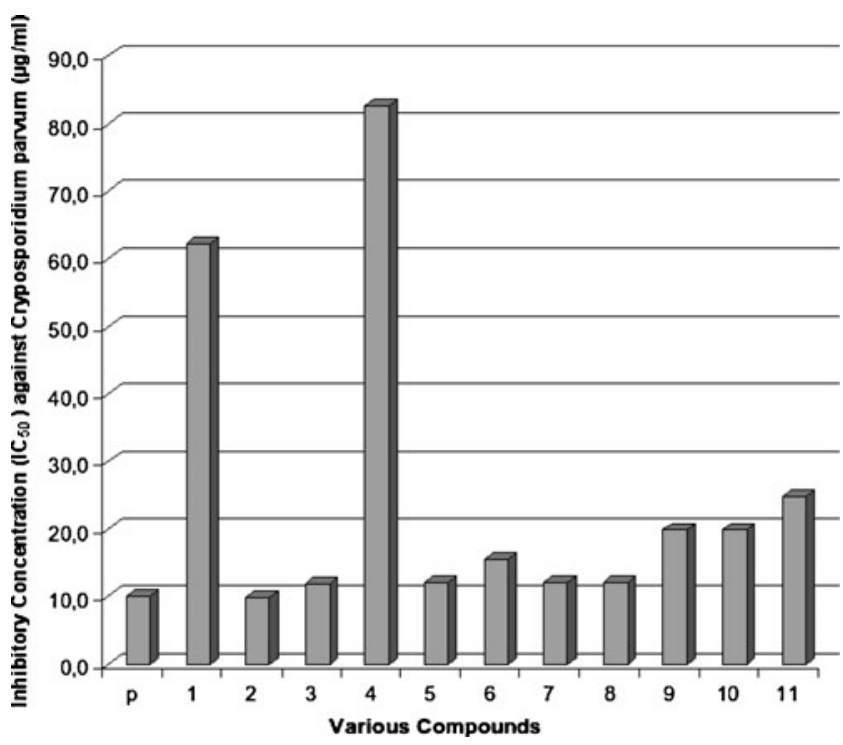

Fig. 2 Inhibitory concentration $\left(\mathrm{IC}_{50}\right)$ of paromomycin and tested benzimidazole derivatives and paromomycin (p). Inhibitory concentration of derivatives 1 and 2 significantly elevated as compared to paromomycin (median $t$ test; $P<0.05$ )

( Kirkegaard \& Perry Laboratories, Inc., Gaithersburg, MD, USA) solution was added. After $10 \mathrm{~min}, 100 \mu \mathrm{l}$ of stop solution (Kirkegaard \& Perry Laboratories) was added to each well, and plates were read at $450 \mathrm{~nm}$ using an enzymelinked immunosorbent assay microplate reader (Molecular Devices, Sunnyvale, CA, USA).

The background absorbance reading taken from wells receiving freeze-thawed oocysts was subtracted from all absorbance readings from drug-treated and control wells, and the percentage of growth inhibition was calculated as $\left[1-\left(\right.\right.$ mean $A_{450}$ of infected wells with drug/mean $A_{450}$ of infected wells without drug) $] \times 100 \%$. The mean values obtained from triplicate readings in two independent experiments were assessed for their significance by the nonparametric test, i.e., median $t$ test. Significance was considered at $P<0.05$.

\section{Results and discussion}

The effect of paromomycin and 11 different benzimidazole derivatives on parasite growth were investigated in cell culture by exposure of $C$. parvum-infected cells to the antimicrobial compounds for $48 \mathrm{~h}$. Paromomycin was used as a reference compound.

The present study demonstrated that the 9 of 11 tested benzimidazole derivatives reduced the number of developmental stages of $C$. parvum in vitro. In particular, compounds 5, 7, and 8 were comparable to paromomycin in inhibiting pathogen growth. Paromomycin is commonly used to treat Cryptosporidium-infected animals and immunocompetent humans. However, this drug is expensive and produces serious side effects, thus cannot be used for immunocompromised individuals with weakened liver functions. Thus, variously substituted benzimidazoles on the benzene nucleus carrying additional nitrobenzylthio substituents at position 2 could be further tested for use in the treatment of cryptosporidiosis in both immunocompetent and immunocompromised individuals.

The mechanisms of Cryptosporidium growth inhibition by the compounds tested in the present study are not clear. However, it is most likely related to the absorption of the drug through Cryptosporidium trophozoite membranes. It is noteworthy that compounds $\mathbf{1}$ and $\mathbf{4}$ being "core structures" for other derivatives were essentially nonactive in the test experiments with their inhibitory concentration values significantly elevated in comparison to paromomycin (median $t$ test; $P<0.05$ ) (Fig. 2). However, introduction of the halogen atoms or carboxyl group onto benzene part of benzimidazole enhances the efficacy of investigated compounds against Crytosporidium. Also, the presence of nitro group or chlorine atoms in the benzylthio part of molecule positively affected antiparasitic activity of the compounds. For this study, we selected only the compounds which have some structural elements typical for nitoxazide (nitrogroup in the side ring) or halogen atoms (chlorophenyltriazole derivatives) (Sharling et al. 2010). It seems also that in the alkylthio residue, the additional functional group is necessary as observed based on anti-C. parvum activity obtained by compounds $\mathbf{1}, \mathbf{2}$, and $\mathbf{3}$. Further studies are necessary to reveal and substantiate the function of the benzimidazole derivatives as prospective anticrysporidial drug candidates.

Testing of the efficacy of the benzimidazole derivative compounds in vitro against developmental stages of Cryptosporidium is the first step in drug testing. Based on the $\mathrm{ID}_{50}$ values obtained in the present study for these 11 compounds, we conclude that all produced an elevated level of effectiveness that warrants the next phase of investigation to focus on toxicity and animal infection testing. However, our attention will be particularly focused on the three compounds, i.e., 5, 7, and $\mathbf{8}$ since their efficacy was shown to be superior to paromomycin.

The ideal drug for treatment of cryptosporidiosis or any other intestinal protozoa infection in immunocompetent and immunocompromised patients should be easy absorbable by the intestinal epithelium (which is site of Cryptosporidium infection) and should be effective at low dosage without producing side effects (Downey et al. 2009). However, if a drug does not produce side effects, the dose and frequency of treatment are irrelevant. The compounds tested in the present study are not watersoluble but soluble in lipids which assures their: (1) emulsification in the intestinal lumen; (2) easy absorption 
by the intestinal epithelium; and (3) a direct inhibitory effect on Cryptosporidium developmental stages covering intestinal epithelium microvilli.

Because there are not enough directly relevant studies and results for treatment of $C$. parvum infections and this genus includes another human infectious species, Cryptosporidium hominis (Xiao et al. 2001), we will test the compounds in animal models. Anti-diarrheal medicine may retard diarrhea, but a health care provider should be consulted before such medicine is administered (Downey et al. 2008). Nitazoxanide is FDA-approved for treatment of diarrhea caused by Cryptosporidium in humans with healthy immune systems and is available by prescription. However, the effectiveness of nitazoxanide in immunosuppressed individuals is unclear.

HIV positive individuals who suspect they have cryptosporidiosis should contact their health care provider. For those persons with AIDS, anti-retroviral therapy that improves the immune status will also decrease or eliminate symptoms of cryptosporidiosis. However, even if symptoms disappear, cryptosporidiosis is often not curable and the symptoms may return if the immune status worsens.

Acknowledgments We thank Dr. Dwight Bowman of Cornell University, College of Veterinary Medicine, Ithaca, New York, USA for providing $C$. parvum oocysts, and the Foundation for Development Diagnostics and Therapy, Warsaw, Poland for providing the compounds for testing.

The study was supported by the Ministry of Science and Higher Education (Poland); grant no.: N N209 371439.

Open Access This article is distributed under the terms of the Creative Commons Attribution Noncommercial License which permits any noncommercial use, distribution, and reproduction in any medium, provided the original author(s) and source are credited.

\section{References}

Anderson VR, Curann MP (2007) Nitazoxanide: a review of its use in the treatment of gastrointestinal infections. Drugs 67:1947-1967

Andrzejewska M, Yepez-Mulia ML, Tapia A, Cedillo-Rivera R, Laudy AE, Starosciak BJ (2004) Synthesis, and antiprotozoal and antibacterial activities of S-substituted 4, 6-dibromo- and 4, 6dichloro-2-mercaptobenzimidazoles. Eur J Pharm Sci 21:323-329

Bennamane N, Zaiona K, AkacemY KR, Bantarzi Y, Bakhata S, Nedjar-Kolli B, Ouhab L (2009) Synthesis of benzimidazole-2thiones from dimedone: an unexpected cyclisation into a fivemembered ring. Org Commun 2:49-59

Downey AS, Chong CR, Graczyk TK, Sullivan DJ (2008) Efficacy of pyrvinium pamoate against Cryptosporidium parvum infection in vitro and in a neonatal mouse model. J Antimicrob Agents Chemother 52:3106-3112

Downey AS, Chong CR, Graczyk TK, Sullivan DJ (2009) In vitro efficacy of pyrvinium pamoate against Entamoeba histolytica and Giardia duodenalis using radiolabeled thymidine incorporation and a SYBR Green I-based fluorescence assay. J Antimicrob Chemother 64:751-754

Dziuban EJ, Liang JL, Craun GF, Hill V, Yu PA, Painter J, Moore M, Calderon RL, Roy SL, Beach ML (2006) Surveillance for waterborne disease and outbreaks associated with recreational water-United States, 2003-2004. Morb Mort Wkl Rep 55:1-24

Fayer R (2004) Cryptosporidium: a water-borne zoonotic parasite. Vet Parasitol 126:37-56

Gargala G, Delaunay A, Favennec L, Brasseur P, Ballet JJ (1999) Enzyme immunoassay detection of Cryptosporidium parvum inhibition by sinefungin in sporozoite infected HCT-8 enterocytic cells. Int J Parasitol 29:703-709

Graczyk TK, Fayer R, Cranfield MR (1997) Zoonotic potential of Cryptosporidium parvum: implications for waterborne cryptosporidiosis. Parasitol Today 13:348-351

Hernández-Luis F, Hernández-Campos A, Castillo R, NavarreteVázquez G, Soria-Arteche $\mathrm{O}$, Hernández-Hernández $\mathrm{M}$, YépezMulia L (2010) Synthesis and biological activity of 2-(trifluoromethyl)-1H-benzimidazole drivatives against some protozoa and Trichinella spiralis. Eur J Med Chem 45:3135-41

Ijaz MK, Suchmann DB, Pugh JC, Graczyk TK, Sattar SA (2000) Evaluation of chloride dioxide as a microbiological water purifier. J Chem Specials Manufact Assoc 23:38-43

Kazimierczuk JA, Upcroft P, Upcroft A, Górska B, Starosciak A, Laudy A (2002) Synthesis, antiprotozoal and antibacterial activity of nitro- and halogeno-substituted benzimidazole derivatives. Acta Biochim Pol 49:185-195

Kazimierczuk Z, Andrzejewska M, Kaustova J, Klimesova V (2005) Synthesis and antimycobacterial activity of 2-substituted halogenobenzimidazoles. Eur J Med Chem 40:203-208

Narkhede HP, More UB, Dalal DS, Mahulikar PP (2007) Solid supported synthesis of 2-derivatives using microwaves. J Sci Ind Res 67:374-376

Pagano MA, Andrzejewska M, Ruzzene M, Sarno S, Cesaro L, Bain J, Elliott M, Meggio F, Kazimierczuk Z, Pinna LA (2004) Optimization of protein kinase CK2 inhibitors derived from 4,5 , 6, 7-tetrabromobenzimidazole. J Med Chem 47:6239-6247

Perez-Villaneuva J, Santos R, Hernández-Campos A, Giulianotti MA, Castillo R, Medina-Franco JL (2010) Towards a systematic characterization of the antiprotozoal landscape of benzimidazole derivatives. Bioorg Med Chem 18(21):7380-7391

Reynoldson JA, Thompson RCA, Horton RJ (1992) Albendazole as a future antigiardial agent. Parasitol Today 8:412-413

Sharling L, Liu X, Gollapalli DR, Maurya SK, Hedstrom L, Boris Striepen B (2010) A screening pipeline for antiparasitic agents targeting Cryptosporidium inosine monophosphate dehydrogenase. PloS Neglected Trop Dis 4(8):e794

Sunderland D, Graczyk TK, Tamang L, Breysee PN (2007) Impact of bathers on levels of Cryptosporidium parvum and Giardia lamblia cysts in recreational beach water. Water Res 41:34833489

Ventura G, Larocca LM, Riccioni ME, Tumbarello M, Lucia MB (1997) Gastric cryptosporidiosis complicating HIV infection: case report and review of the literature. Eur J Gastroenterol Hepatol 9:307

Woods KM, Nesterenko MV, Upton ST (1995) Development of a microtitre ELISA to quantify development of Cryptosporidium parvum in vitro. FEMS Microbiol Lett 128:89-94

Xiao L, Singh A, Limor J, Graczyk TK, Gradus S, Lal AA (2001) Molecular characterization of Cryptosporidium oocysts in samples of raw surface and wastewater. Appl Environ Microbiol 67:1097-1101 